\title{
Costs associated with the evolution of selfing in North American populations of Arabidopsis lyrata?
}

\author{
Jens Joschinski ${ }^{1,2} \cdot$ Mark van Kleunen ${ }^{1}$ • \\ Marc Stift ${ }^{1}$
}

\begin{abstract}
Selfing can evolve if the transmission advantage of selfers outweighs the negative effects of inbreeding depression. It has been hypothesised that on the long term, selfing lineages are an evolutionary dead end, in part due to genetic degradation resembling that of Muller's ratchet in asexual lineages. There is a lack of empirical evidence for costs of selfing due to genetic degradation in recently evolved selfers. We tested whether such costs are apparent in recently established selfing populations of the generally outcrossing species Arabidopsis lyrata. Specifically, we compared selfing and outcrossing populations in their growth performance, and for traits that play a putative role in defence against herbivores. In line with our expectations, selfing populations had reduced germination rates, growth however was similar to outcrossing populations. Plants from selfing popu lations showed no consistent reduction in herbivore defence traits, and were equally palatable to caterpillars of the moth Mamestra brassicae. There were also no differences between outcrossers and selfers in phenotypic plasticity for putative defence traits and palatability after induction by herbivores. Overall, we interpret our results as showing some evidence for persistent costs of selfing due to drift or inbreeding load in terms of reduced seedling establishment, but providing no support for the hypothesis that selfing populations should be more susceptible to generalist herbivores, or rely more on induced defence.
\end{abstract}

Marc Stift

marc.stift@uni konstanz.de; marcstift@gmail.com

1 Ecology, Department of Biology, University of Konstanz, Universitätsstrasse 10, 78457 Constance, Germany

2 Present Address: Department of Animal Ecology and Tropical Biology, Biocentre, University of Würzburg, Am Hubland, 97074 Würzburg, Germany 
Keywords Herbivory · Evolution of selfing · Resistance · Drift load · Inbreeding depression · Mating system evolution - Arabidopsis lyrata - Mamestra brassicae . Trichomes · Induced defence

\section{Introduction}

Selfing has evolved repeatedly from outcrossing ancestors in many different plant families (Igic et al. 2008). The evolution of selfing frequently requires the breakdown of a self incompatibility system, followed by changes in floral morphology and/or the timing of anthesis and stigma receptivity. Whether selfing will establish in a population after the initial break down of the self incompatibility system, and will maintain itself in the long run depends besides stochastic events on the benefits and costs of selfing.

In the short term, selfing provides a transmission advantage over outcrossing (Fisher 1941), and assures reproductive success in situations where partners or pollinators are rare (Darwin 1876). However, selfing results in increased homozygosity (Wright et al. 2008), which can cause an immediate reduction in fitness (i.e., inbreeding depression; see Charlesworth and Charlesworth 1987 for a review). In the long term (i.e., on evolutionary time scales), the persistence of newly formed selfers depends on further trade offs. On the one hand, selfing may allow for a reduced investment in floral display and rewards for pollinators, which may save resources and reduce florivory [references in Sicard and Lenhard 2011)]. On the other hand, selfing negates the main advantages of sex genetic exchange and the creation of novel genetic combinations (Barton and Charlesworth 1998). This makes recombination less effective, which should reduce the adaptive potential of selfers (Stebbins 1957), and hamper the removal of deleterious mutations linked to genes under positive selection (Barton and Charlesworth 1998). The resulting genetic degrada tion in selfing lineages (Heller and Maynard Smith 1978) is similar to that expected for asexual organisms, and is known as Muller's ratchet (Muller 1964). The predicted reduction of adaptive potential and genetic degradation have led to the so called dead end hypothesis, which states that selfing lineages do not have the potential to found new evolutionary lineages, and so are dead ends on evolutionary time scales (Stebbins 1957).

The dead end hypothesis has three prerequisites: (1) the transition to selfing should be irreversible, (2) selfers should have a reduced adaptive potential, and (3) there should be persistent and ever increasing fitness costs to selfing due to fixation of pre existing and newly formed deleterious mutations. Phylogenetic approaches have indicated that transi tions from outcrossing to selfing are more frequent than vice versa, and thus indeed appear to be irreversible (Ioerger et al. 1990; Takebayashi and Morrell 2001; Igic et al. 2006). Although only a few studies have demonstrated a reduced adaptive potential in selfing lineages [see references in Takebayashi and Morrell (2001)], the strongly reduced genetic diversity documented for selfers is certainly suggestive (Foxe et al. 2010; but see Wright et al. 2013). Empirical evidence for genetic degradation in selfing lineages is, however, still lacking. Such evidence would require comparing the fitness of selfing species with their closely related outcrossing ancestors, but such comparisons are problematic because diverged species inevitably have different currencies of fitness. On shorter time scales (i.e., within species), this is less of a problem. Hence, comparing fitness components of selfing populations with outcrossing populations of the same species provides a way to test for potential costs of selfing. 
Inbreeding depression and genetic load may affect life history traits such as germination success, relative growth rates and reproductive output. Furthermore, inbreeding may depress tolerance to adverse environmental conditions and, for example, affect resistance against herbivores or pathogens. Outcrossing populations of Arabidopsis lyrata (L.) O'Kane \& Al Shehbaz were not more resistant against the oomycete pathogen Albugo candida (Pers.) Kuntze, but response was more variable in selfing populations (Hoebe et al. 2011). Herbivory has been shown to magnify inbreeding depression (Hayes et al. 2004; Stephenson et al. 2004; Leimu et al. 2008) as well as outbreeding depression (Leimu and Fischer 2010). Indeed, antagonists have frequently been implied as a selective force favouring outcrossing in plants (Levin 1975; Busch 2004). Selfing populations may also simply lack the variation to evolve defences against generalist herbivores (Johnson et al. 2009). Given the effect of herbivores on the degree of inbreeding depression, it seems likely that herbivores may also help to reveal costs of selfing in already established selfing populations. However, to our knowledge, traits related to resistance against herbivores have not been compared yet between selfing and outcrossing populations of a species.

The North American species A. lyrata offers a rare opportunity to test whether direct and/or hidden costs are associated with selfing. The species is mostly self incompatible, with consequently high outcrossing rates $\left(t_{m}>0.83\right.$; Table 1$)$, but in a few populations self incompatibility has broken down, and selfing has become the predominant mode of reproduction (Mable et al. 2005; Mable and Adam 2007; Foxe et al. 2010). We tested whether these selfing populations (that have outcrossing rates $t_{m}$ ranging from 0.09 to 0.41 ; Table 1) show a reduced performance in traits with a direct effect on fitness, i.e., life history traits (germination, early growth), and in terms of traits potentially involved in plant defence, which are expected to only affect fitness in the presence of herbivores. For the latter, we specifically looked at trichome density, specific leaf area (SLA) and leaf dry matter content (LDMC), all traits that are known to vary within and between populations (own observations; Karkkainen and Agren 2002; Puentes and Agren 2013), and to be involved in defence against herbivores (Vergeer and Kunin 2011). Furthermore, we tested for general defence costs associated with selfing by comparing the performance of cater pillars of the generalist herbivore Mamestra brassicae (L.) on plants from selfing and outcrossing populations. Trichome density, SLA, LDMC and caterpillar performance were assessed again after a lag period to test for potential differences in induced responses and induced resistance. Our study identified that plants from selfing populations of A. lyrata suffered from reduced germination rates, but did not differ from plants from outcrossing populations in growth, expression of putative defence traits, palatability to caterpillars of the generalist herbivore $M$. brassicae, and plasticity in response to herbivory.

\section{Materials and methods}

\section{Study species and seed collection}

Arabidopsis lyrata (L.) O'Kane \& Al Shehbaz has a circumpolar distribution (Ross Ibarra et al. 2008). It is exclusively self incompatible on the European continent, and thus obligately outcrossing, but has made a transition to selfing in some North American populations (Mable et al. 2005; Mable and Adam 2007; Foxe et al. 2010). A. lyrata seeds were field collected in 2011 (kindly provided by Dr. Barbara Mable, University of Glas gow) from six outcrossing and four selfing populations in North America. The collections contained 215 distinct seed families, with 330 seed families per population (Fig. 1; 


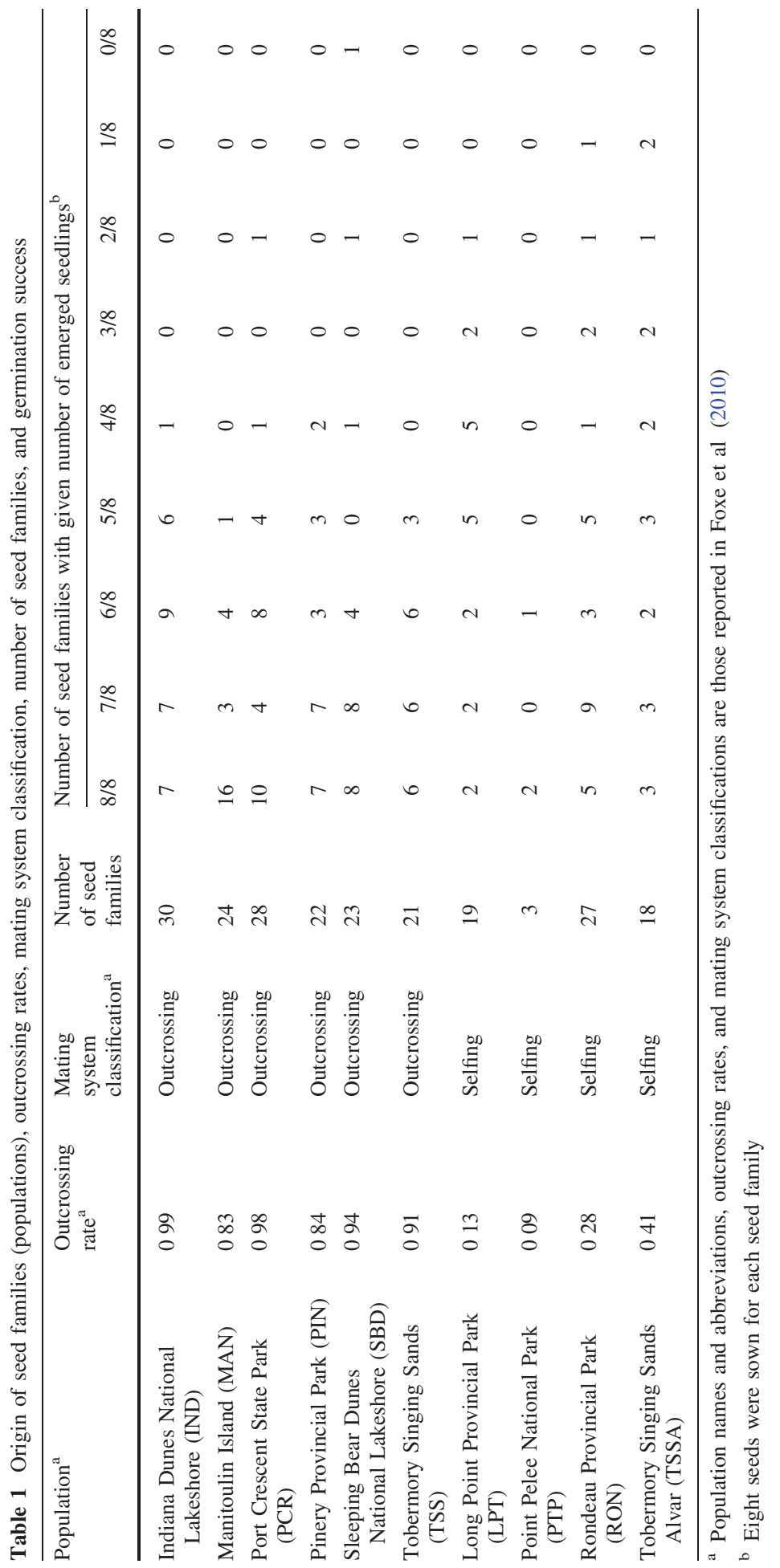




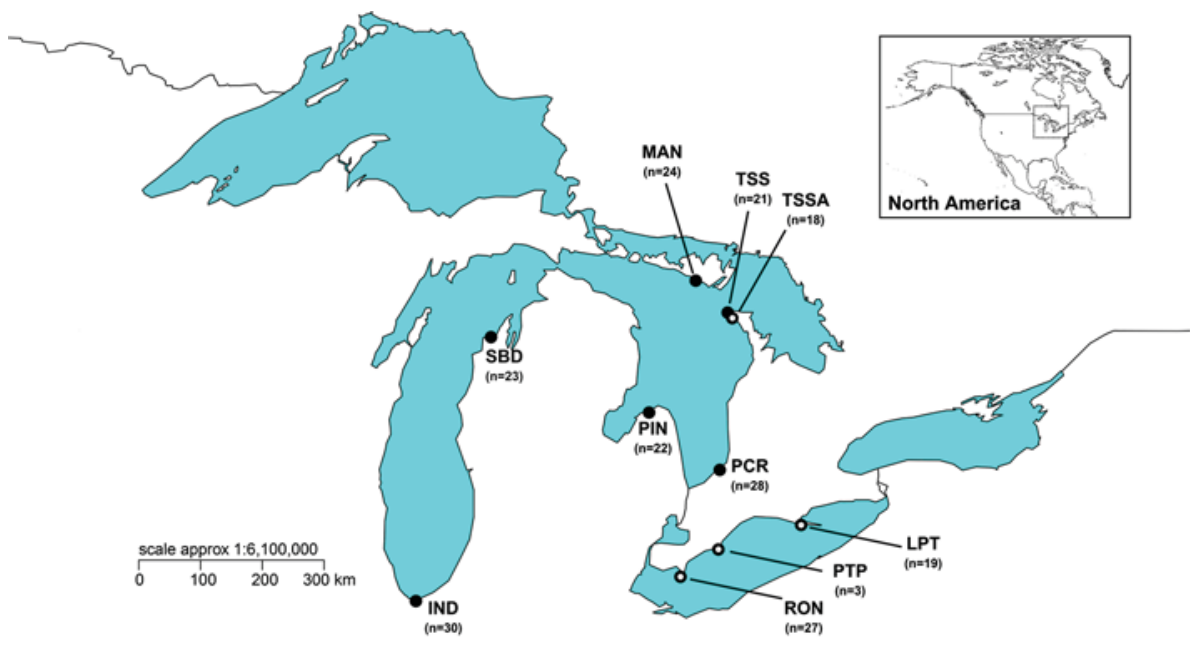

Fig. 1 Sampling localities of outcrossing (closed circles) and selfing (open circles) populations of A. lyrata

Table 1 for more details). There were no obvious habitat or climatic differences between outcrossing and selfing populations.

\section{Germination experiment}

To test for differences in germination between the selfing and outcrossing populations, seeds were sown in eight 54 well quickpot trays (QP 54/5.5R, HerkuPlast Co., Ering am Inn, Germany), filled with $80 \mathrm{~cm}^{3}$ per well of a peat based substrate (Topferde ${ }^{\circledR}$, Ein heitserde Co., Sinntal Altengronau, Germany; pH 5.8; 2.0 g/l KCl; 340 mg/l N; 380 mg/l $\mathrm{P}_{2} \mathrm{O}_{6} ; 420 \mathrm{mg} / \mathrm{l} \mathrm{K} 2 \mathrm{O} ; 200 \mathrm{mg} / \mathrm{l} \mathrm{S} ; 700 \mathrm{mg} / \mathrm{l} \mathrm{Mg}$ ). The substrate was moistened with water containing a small dose of a $2 \%$ suspension of Bacillus thuringiensis subsp. israelensis against fungus gnats (Neomück ${ }^{\circledR}$, Neudorff Co., Emmertal, Germany).

On January 12 and 13, 2012, we sowed eight seeds from each of the 215 seed families (totalling 1720 seeds). We randomly assigned sets of four seeds from the same seed family to each well, such that populations were evenly distributed over the eight quickpot trays, and two sets of seeds from the same seed family were not placed in the same quickpot tray. Plants were grown in a growth chamber with a $16 / 8 \mathrm{~h}$ day/night cycle at $20 / 14{ }^{\circ} \mathrm{C}$ and humidity levels of $\sim 60 \%$. To minimize effects of tray positioning, we rotated the posi tions of the trays six times per week. We estimated germination rates and timing for all eight siblings, based on daily surveys (only plants with fully developed and unfolded cotyledons were considered to have germinated).

\section{Experimental design}

Seeds started germinating 5 days after sowing, but most seeds germinated after 1012 days (Fig. S1). After 24 days, $78.8 \%$ of all seeds had germinated, and after that hardly any further germination was observed (Fig. S1). After 2526 days, we selected four siblings per seed family as base material for the growth assessment (and herbivory trials, see following section). Selection was based on the following criteria: 
(1) If possible, we randomly selected four siblings that germinated 1012 days after sowing; (2) if criterion i yielded fewer than four siblings of a given seed family, we randomly selected the required additional number of siblings from those that had germi nated after 8, 9, 13 or 14 days; (3) if criterion i and ii still yielded fewer than four siblings, we randomly selected the required additional number of siblings from those that had germinated earlier than 8 or later than 14 days after sowing. These criteria meant for the plants in the experiment, for outcrossing and selfing populations respectively, that 69 and $62 \%$ had germinated 1012 days after sowing, 14 and $13 \%$ 8, 9, 13 or 14 days after sowing, and 17 and $25 \%$ earlier than 8 , or later than 14 days after sowing. For 15 of the 215 seed families, we had $<4$ siblings because the germination rate was $<50 \%$. Therefore, 832 seedlings were selected for the experiment.

We transplanted the selected seedlings into individual pots filled with approximately $250 \mathrm{~cm}^{3}$ of the same substrate as had been used for germination. 8 of the 832 siblings died after transplanting. The design was then split into two climate controlled greenhouse compartments ( $16 / 8 \mathrm{~h}$ day/night cycles with temperatures ranging from 24 to $30{ }^{\circ} \mathrm{C}$ during daytime and around $18{ }^{\circ} \mathrm{C}$ at night), in such a way that two seedlings of each of the 215 seed families were randomly assigned to each cubicle. Within the cubicles, we followed a randomised block design with blocks formed by 16 trays each containing 28 positions. We randomly assigned the 824 successfully transplanted seedlings to one of the 896 positions within the trays, with the constraint that populations were evenly distributed over trays, and avoiding more than one sibling from the same seed family (i.e., from the same mother plant) in a single tray. This way, 71 empty positions were randomly distributed over the trays. Plants were watered from below using felt mats, and fertilized regularly (Universol Blue, Scotts International, Geldermalsen, The Netherlands).

\section{Growth-rate measurements}

To test for differences in growth, 1 week after transplanting (33 days after sowing), we counted the number of leaves (A). For the largest leaf of each plant, we measured the lengths of the petiole and leaf blade (L), and the maximum width (W). These measure ments were repeated 40 days after sowing in order to calculate the growth rate according to the following formulae $R G R=\ln \left(S_{40} / S_{33}\right)$. Here, $S$ represents the size of the plant cal culated as $S=A \times L \times W$.

\section{Constitutive trichome density (before induction by caterpillars)}

To test for differences in traits that likely play a role in defence against herbivores, at 5257 days after sowing, we assessed the density of trichomes on the leaf blades of the third youngest leaf of each plant. Trichome counting was done under a binocular micro scope with $20 \times$ magnification within a square of $10 \times 10 \mathrm{~mm}$ centred on the mid vein at roughly $10 \%$ of the blade length away from the leaf tip. On leaves narrower than $10 \mathrm{~mm}$, the area for trichome counting was reduced to a rectangular area with a maximum length:width ratio of 0.5 .

\section{First herbivore trial}

To test for constitutive differences in palatability to generalist herbivores and to induce defence, we conducted a bio assay with caterpillars of M. brassicae (L.), 47 days after the 
trichome measurements. For this, we used two surviving siblings of each seed family from each growth chamber (totalling 824 of the original 832 plants). On one of these two, we placed a 3rd 4th instar caterpillar that had been starved for $24 \mathrm{~h}$, and allowed it to feed on the plants for $72 \mathrm{~h}$. The second served as a control for the second herbivory trial. To prevent caterpillar escape, all plants (including the controls) were individually covered with a nylon gauge bag (mesh size of approximately $0.5 \mathrm{~mm}$ ), held up by metal frames and tightly fixed to the pot using elastic bands. To test whether caterpillar performance differed between selfing and outcrossing populations on non induced plants, we weighed cater pillars immediately before and after the feeding phase. Of the initial 824 plants in the design, only 795 could be used for analysis because some of the caterpillars had escaped or died. Feeding damage was clearly visible on all herbivore treated plants. No caterpillars started pupating for the 7 days following the experiment, so ontogenetic effects of the caterpillars are unlikely to have affected the results.

Testing for plasticity in putative defence traits (trichome density, specific leaf area and leaf dry matter content) and induced resistance (larval performance)

To test whether herbivory induced an increase in trichome density, we repeated the tri chome counts using the same method as outlined above, and calculated the difference between the trichome density before and after the first herbivore trial. For the plants that would be exposed to herbivores a second time (half of the plants in the design, all plants from one of the growth chambers), trichomes were counted 79 days after the first her bivore induction. Then, to test whether the first herbivore trial had induced a higher resistance, we placed a 3rd 4th instar caterpillar that had been starved for $24 \mathrm{~h}$, and allowed it to feed on the plants for $72 \mathrm{~h}$. To test whether caterpillar performance differed among induced and non induced plants, and whether this effect depended on mating system, we weighed caterpillars immediately before and after the feeding phase.

For the remaining half of the plants (from the second growth chamber), trichomes were counted 1416 days after the first trial, and these plants were also used to test whether herbivory had induced an increase in traits relevant for food quality: SLA and LDMC. As these traits cannot be assessed without damaging the plants, these plants were not used to test for induced resistance. We sampled the third youngest leaf (i.e., the oldest of the leaves that had developed after the herbivory treatment), and measured its total leaf area with a LI3100 Leaf Area Meter (LiCor, Lincoln, NE, USA), and determined the fresh and dry weight (after drying for at least $72 \mathrm{~h}$ at $80{ }^{\circ} \mathrm{C}$ ). Subsequently, we calculated SLA as the area per dry weight and LDMC as the ratio between dry weight and fresh weight.

\section{Statistical analysis}

Of the 824 plants in the experiment, 11 were excluded from analysis (in four cases the label went missing; in six cases plants died after the first measurement; in one case the ger mination date had not been recorded). We used R version 3.1.0 (R Core Team 2014) for all statistical analyses. To test for differences between outcrossing and selfing populations, we used the lmer and glmer functions of the lme4 package (Bates et al. 2014) to build (generalized) linear mixed models. The base model consisted of Mating System as the fixed term, a random term Tray, and a nested random term of Seed Family nested in Population nested in Mating System. For the difference in trichome density before and after herbivore induction, we included the fixed effects Herbivory Treatment (with or without caterpillars) and the time point (TP) for counting trichomes (6 9 days after 
induction or 1318 days after induction). Since none of the interactions between the main effects were significant (evaluated by model comparison), we excluded them from the model. For the analysis of SLA and LDMC, we included the fixed effect Herbivory Treatment (with or without caterpillars). Since the interaction between Mating System and Herbivory Treatment was not significant (model comparison), we excluded the interaction from the model.

For the response variable germination success (yes or no), we used a binomial error distribution. For the response variables growth rate, constitutive trichome density, con stitutive larval growth before herbivore induction, difference in trichome density before and after induction, and larval growth after induction, we used a Gaussian error distri bution. For all response variables (except germination rate) the natural log of germination time (days it took from sowing to germination) was included as a covariate. For the trichome related traits, we used the leaf sizes of the leaves on which trichomes were counted as additional covariates.

The residuals of all Gaussian models were examined visually for deviations from normality and homoscedasticity. Where required, response variables were transformed to improve residual structure: plant growth rate was Box Cox transformed using the formula $Y_{\text {transformed }}=\left(Y^{\lambda}-1\right) / \lambda$ with $\lambda=1.5$; constitutive trichome density and SLA were square root transformed as $Y_{\text {transformed }}=Y^{0.5}$; and LDMC was $\log _{\mathrm{e}}$ transformed as $Y_{\text {transformed }}=\log _{e}(Y)$; all other traits (germination rate, the difference in trichome density before and after herbivore induction, caterpillar growth before induction and caterpillar growth after induction) were not transformed before analysis. For all models, the signifi cance of the fixed effect Mating System was tested by removing it from the model and using a log likelihood ratio test (LRT) to compare the reduced model to the full model. For the models including SLA, LDMC and caterpillar growth rate, the significance of the fixed effects Mating System, Herbivory Treatment, and their interaction were tested by sequential model reduction and LRT. For the difference in trichome density, the signifi cance of the fixed effects Mating System, Herbivory Treatment, their interaction, and TP was assessed in the same manner. For the model comparisons, the models were run using maximum likelihood estimation (see Zuur et al. 2009).

\section{Results}

\section{Germination rates and relative growth}

Germination rates (i.e., proportion of germinated seeds) were significantly lower (likeli hood ratio test $\left.\chi_{d f}^{2}{ }_{1}=7.26, p=0.0070\right)$ for selfing populations compared to outcrossing populations (68.3 vs. $83.6 \%$; Fig. 2a). The relative growth rate (based on the product of the length and width of the largest leaf, and the leaf number) did not significantly differ between outcrossing and selfing populations (Fig. 2b, likelihood ratio test $\chi_{d f}^{2}=1.36$, $p=0.244)$.

\section{Constitutive trichome density (before herbivory trial) and caterpillar performance on non-induced plants}

Trichome densities before the herbivore trial varied from 0 to 2.56 trichomes $/ \mathrm{mm}^{2}$, with an overall mean of 0.56 . Variation in trichome densities (Fig. 2c) was not explained by the 

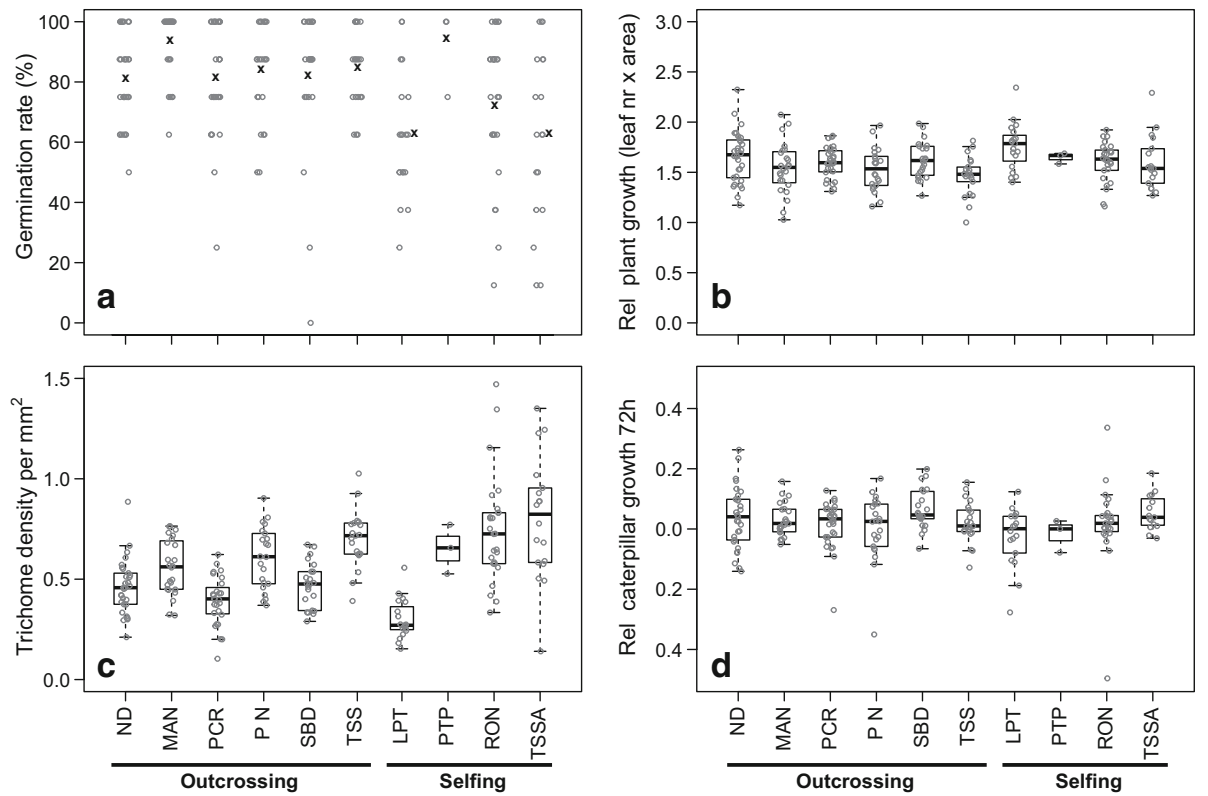

Fig. 2 Summary of trait variation within and between outcrossing and selfing populations: germination rate, with times symbol indicating the mean (a); relative growth rate between 33 and 40 days after sowing (b), trichome density per $\mathrm{mm}^{2}$ (c), relative growth of $M$. brassicae caterpillars over a period of $72 \mathrm{~h}(\mathbf{d})$. Boxplots were based on means per seed family, individual grey circles indicate means per seed family. Boxes represent the area from the first to the third quartile (the interquartile range: IQR), with a horizontal line indicating the median. Whiskers extend to the lowest/highest data point within 1.5 times the IQR

Mating System (likelihood ratio test $\chi_{d f}^{2} 1_{1}=0.5649, p=0.4523$ ). Caterpillar growth rate before induction ranged from -0.49 to 0.37 , with a mean of 0.025 , and did not significantly differ (likelihood ratio test $\chi_{d f}^{2}{ }_{1}=0.877, p=0.349$ ) between outcrossing and selfing populations (Fig. 2d). Trichome density did not affect caterpillar growth rate (likelihood ratio test $\chi_{d f \quad 1}^{2}=0.411, p=0.522$ ).

\section{Effects of herbivore induction on trichome density, specific leaf area (SLA), leaf dry matter content (LDMC), and caterpillar performance}

The difference in trichome density between the assessment before the herbivore trial and after the herbivore trial ranged from -1.66 to 2.90 trichomes per $\mathrm{mm}^{2}$ with a mean of 0.019. The difference in density was larger for plants that had been exposed to herbivores compared to control plants (Fig. 3a; Table 2), but both ranges included zero (no change). Mating System did not have a significant effect, but there was a significant interaction between Mating System and Herbivore Treatment (Table 2), because plants from outcrossing populations responded more strongly to herbivory (Fig. 3a).

The SLA ranged from 72 to $996 \mathrm{~cm}^{2} / \mathrm{g}$ with a mean of 210 . Herbivore Treatment had a significant effect on SLA (Table 2) with decreased SLA in induced plants (Fig. 3b). Mating System did not have a significant effect on SLA, and there was no interaction with Herbivore Treatment (Table 2). LDMC ranged from 0.045 to $0.438 \mathrm{~g} / \mathrm{g}$, with a mean of 0.209 (Fig. 3c). Herbivore Treatment, Mating System, and their interaction had no 

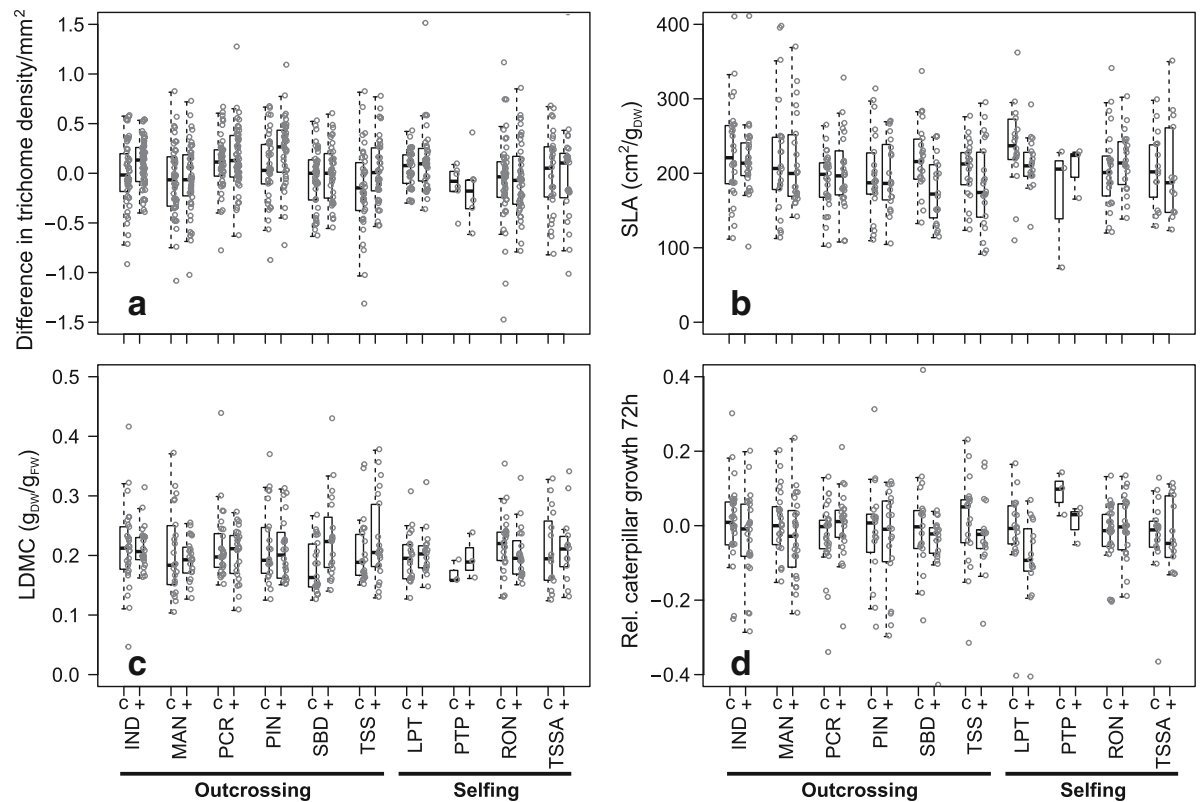

Fig. 3 Comparison between outcrossing and selfing populations, for non induced control plants $(C)$ and plants induced by M. brassicae caterpillars (plus symbol): difference in trichome density before and after first herbivory trial (a), specific leaf area (SLA) (b), leaf dry matter content (LDMC) (c), relative growth of $M$. brassicae caterpillars over a period of $72 \mathrm{~h}(\mathbf{d})$. Boxplots were based on means per seed family, individual grey circles indicate the means per seed family. Boxes represent the area from the first to the third quartile (the interquartile range: IQR), with a horizontal line indicating the median. Whiskers extend to the lowest/highest data point within 1.5 times the IQR

significant effect on LDMC (Table 2). A similar pattern emerged for caterpillar growth rate after induction (Fig. 3d; Table 2).

\section{Discussion}

Our main finding is that plants from selfing populations of the North American species $A$. lyrata did not differ from plants from outcrossing populations in constitutively expressed traits related to herbivore defence, i.e., trichome density (Fig. 2c) and caterpillar performance (Fig. 2d). After feeding by the generalist herbivore M. brassicae, selfing and outcrossing plants showed some differences in phenotypic plasticity for defence traits, but the differences were small in magnitude (Fig. 3a c). There was no evidence of induced resistance, i.e., previous exposure to herbivores did not decrease caterpillar performance in a second her bivory trial (Fig. 3d). However, plants from selfing populations did have significantly lower germination rates (Fig. 2a), while relative growth rates were not affected (Fig. 2b).

\section{Differences in performance-related traits between outcrossing and selfing populations as estimates of costs of selfing}

Our finding of only modest costs of selfing (reduced germination rates; Fig. 2a) is in line with a study in the same species, which additionally showed that selfing populations 
Table 2 Difference in trichome density, specific leaf area, leaf dry matter content and caterpillar growth rate on plants not previously exposed to caterpillar feeding (control) and plants exposed to $72 \mathrm{~h}$ of feeding by $M$. brassicae caterpillars (induced)

\begin{tabular}{|c|c|c|c|c|}
\hline & $\begin{array}{l}\text { Difference in } \\
\text { trichome density }^{\text {a }}\end{array}$ & $\begin{array}{l}\text { Specific } \\
\text { leaf area }\end{array}$ & $\begin{array}{l}\text { Leaf dry } \\
\text { matter content }\end{array}$ & $\begin{array}{l}\text { Caterpillar } \\
\text { growth rate }\end{array}$ \\
\hline \multicolumn{5}{|l|}{ Outcrossing populations } \\
\hline Control & $0.0249^{\mathrm{b}}$ & 214.7 & 0.206 & 0.0140 \\
\hline Induced & $0.0791^{\mathrm{b}}$ & 199.3 & 0.213 & 0.0282 \\
\hline \multicolumn{5}{|l|}{ Selfing populations } \\
\hline Control & $0.0375^{\mathrm{b}}$ & 206.3 & 0.199 & 0.00646 \\
\hline Induced & $0.0319^{\mathrm{b}}$ & 209.1 & 0.203 & 0.0352 \\
\hline \multicolumn{5}{|c|}{ Likelihood ratio tests (LRT) for fixed effects ${ }^{c}$} \\
\hline $\begin{array}{l}\chi_{d f 1}^{2}(p \text { value }) \text { for LRT } \\
\quad \text { of mating system (MS) }\end{array}$ & $1.770(0.183)$ & $0.033(0.856)$ & $0.0876(0.77)$ & $0.779(0.38)$ \\
\hline $\begin{array}{l}\chi_{d f 1}^{2} 1(p \text { value }) \text { for LRT } \\
\quad \text { of herbivore treatment }(\mathrm{HT})\end{array}$ & $8.01(0.00465)$ & $4.15(0.0417)$ & $2.60(0.11)$ & $2.57(0.11)$ \\
\hline $\begin{array}{l}\chi_{d f}^{2} 1(p \text { value }) \text { for LRT } \\
\quad \text { of } \mathrm{MS} \times \mathrm{HT} \text { interaction }\end{array}$ & $3.90(0.0484)$ & 0.0196 (0.889) & $0.0031(0.956)$ & $0.606(0.436)$ \\
\hline $\begin{array}{l}\chi_{d f 1}^{2}(p \text { value }) \text { for LRT } \\
\text { of time point (TP) }\end{array}$ & $0.902(0.342)$ & NA & NA & NA \\
\hline
\end{tabular}

${ }^{a}$ Because the second assessment of trichome densities was done at two discrete time points, time point was included as a fixed effect in the model. Interactions with time point were not included. The model further included the natural log of the leaf lengths on which the trichomes were counted as covariates

b Mean value over the two time points that the second trichome density was assessed

c We used linear mixed effect models that included a fixed part with mating system, herbivore treatment and their interaction and the natural log of time to germination as a covariate. The random part included seed family nested in population, and tray. The significance of the main effects was evaluated through model comparisons and likelihood ratio tests; significant values $(p<0.05)$ are highlighted in bold

benefited more from between population crosses than outcrossing populations (Willi 2013). The modest costs of selfing were also reflected by the growth rates in the period from 33 to 40 days after sowing, as they did not differ between selfing and outcrossing populations (Fig. 2b). However, our growth rate estimates (and herbivore related traits discussed below) might underestimate the real costs of selfing, because they were based on an intentionally biased sample: we selected seedlings that had germinated 1012 days after sowing, in order to control for age and size, and thereby possibly removed the weaker plants from the experiment.

Due to the reduced effective population size of selfers (Wright et al. 2008), Willi (2013) suggested that drift load and accumulation of deleterious alleles may explain the apparent costs of selfing. Selfing populations in A. lyrata form population genetic clusters with different outcrossing populations (Hoebe et al. 2009; Foxe et al. 2010) in an area that was covered by the Wisconsin Ice Sheet during the last Glacial Maximum, which lasted until around 10,000 years ago (Lewis et al. 2008). This gives only a limited window for mutation accumulation, although as little as 25 generations have proven to be sufficient for phenotypic changes attributable to mutation among A. thaliana mutation accumulation lines (Shaw et al. 2000; Rutter et al. 2010). Interestingly, these studies inferred that a larger than theoretically expected fraction of mutational effects was beneficial or neutral and not deleterious. More research is needed to assess the potential role of mutation accumulation 
in the long term maintenance of selfing and outcrossing populations of A. lyrata, and more in general to address whether Muller's ratchet (Muller 1964) can lead to genetic degra dation in (partially) selfing lineages (Heller and Maynard Smith 1978).

Given the complexity of our experimental design (including repeated herbivory trials), which logistically prohibited the estimation of more direct fitness measures, we limited our comparison of performance to germination rate and seedling performance (growth rate). Previous evidence in two populations of the European subspecies A. lyrata petraea had indicated the importance of early life history traits for inbreeding depression, with sig nificant inbreeding depression effects throughout the life cycle, but most pronounced effects $(\sim 60 \%)$ for seed production (Sletvold et al. 2013). In a single outcrossing pop ulation of North American A. lyrata, there was strong inbreeding depression (up to $40 \%$ ) for germination rate, and less severe but still significant inbreeding depression (up to $10 \%$ ) for relative growth rate (Stift et al. 2013). We are unaware of published estimates of inbreeding depression for more direct measures of fitness such as seed or fruit set, pre sumably due to the difficulty of obtaining estimates that allow comparisons between self compatible and self incompatible plants, and for perennial plants. Willi (2013) attempted to obtain multiplicative measures of fitness by following the fruit set and flower production of plants from different crosstypes over multiple years. Although this has probably resulted in the best available data on costs of selfing beyond inbreeding depression, it still ignores seed set and seed quality, that are arguably among the most important components of fitness, yet al.so the most difficult and labour intensive to estimate.

It is also important to realise that, rather than reflecting a cost of selfing due to genetic degradation, the apparent reduced performance of selfers in terms of germination rate (our results) or in general (Willi 2013) may be explained by inherent differences in habitat or alternative reproductive strategies. Selfers are more probable to colonize new, harsher habitats (Baker 1955; Stebbins 1957) and are less pollen limited than outcrossers (Burd 1994). As we used seeds directly collected from the field, our design has not excluded maternal environmental effects. However, selfing and outcrossing populations occur in similar sand dune habitats (Mable and Adam 2007), making differences due to maternal effects unlikely. The environmental conditions during which selfing was selected may also have driven alternative trade offs between progeny quality and quantity. Both our own work and that of Willi (2013) have not considered quantity (i.e., seed set). Moreover, since outcrossing European A. lyrata is known to have a seed bank (Falahati Anbaran et al. 2011), changes in levels of dormancy associated with the evolution of selfing could provide an alternative explanation for our finding of reduced germination rates in selfing popula tions. Finally, since purging of mildly deleterious alleles is difficult (Charlesworth et al. 1990), reduced germination may reflect persistent inbreeding load (i.e., inbreeding depression). The relative importance of dormancy and persistent inbreeding load remains to be investigated in more detail.

\section{Constitutive differences in traits related to plant defence}

Trichomes have been shown to be important in resistance against herbivores in the European subspecies of A. lyrata (Clauss et al. 2006; Kivimaki et al. 2007; Loe et al. 2007; Sletvold et al. 2010), and trichome density is highly variable within and between popu lations (Karkkainen and Agren 2002; Vergeer and Kunin 2011; Puentes and Agren 2013). Our results also revealed high variation in trichome density both within and among pop ulations of the North American subspecies (Fig. 2c), but trichome density did not affect the performance of $M$. brassicae caterpillars. Trichome densities were of comparable 
magnitude to European populations (e.g., see Puentes and Agren 2013). However, unlike in the European range (Loe et al. 2007), we found no glabrous morphs within populations, although plants from the LPT population had less trichomes than any of the other popu lations (Fig. 2c). Apart from this single population, there were no consistent differences in trichome density between selfing and outcrossing populations, and it remains unclear what drives differences in trichome density within the selfing and outcrossing North American populations.

Rather than looking at defence traits individually, using a generalist herbivore (folivore) provides an integral test for differences in traits associated with nutritional quality (Agrawal 2000; Campbell and Kessler 2013). Our feeding trial indicated that M. brassicae caterpillar weight gain was not affected by population or mating system, which does not support the macro evolutionary hypothesis that selfing should frequently result in evolution of increased susceptibility to generalist herbivores (Johnson et al. 2009). This may be because the selfing populations we studied here are of relatively recent origin and not exclusively selfing (Table 1). Moreover, it should be noted that overall the caterpillars performed rather poorly on A. lyrata. The combination of a novel food source (plants rather than medium) and the stress of the caterpillar transfer from the laboratory culture to the plants may underlie the fact that a large proportion of caterpillars lost weight. On the other hand, Mamestra caterpillars are frequently used in similar feeding trials (Gols et al. 2008; van Leur et al. 2008), and its weight gain during trials has been considered a reliable indicator of palatability. Our data therefore suggest that A. lyrata plants have a high constitutive resistance against $M$. brassicae, independent of mating system. Contrastingly, in a comparison among self incompatible and compatible Solanaceae species pairs, self incompatible species had a higher constitutive resistance against caterpillars of the family specialist Manduca sexta (Campbell and Kessler 2013). A similar experiment in the Brassicaceae is needed to test whether our finding of no differences in nutritional quality for M. brassicae caterpillars between selfing and outcrossing populations of A. lyrata represents a family specific pattern, or is specific to A. lyrata.

\section{Plasticity in defence traits and induced resistance}

In the Solanaceae, self compatible taxa had a higher inducible resistance than self in compatible taxa (Campbell and Kessler 2013). Here, we found that feeding by caterpillars of the generalist $M$. brassicae induced an increase of 8 trichomes per $\mathrm{cm}^{2}$ in trichome density in outcrossing populations of A. lyrata (Table 2). However, this increase did not result in significantly reduced larval performance in our experiment (no effect of herbivore treatment in Table 2), and including trichome density in the fixed part of the model did not improve model fit. Similarly, there was a $<5 \%$ but significant overall decrease in SLA (Table 2), but LDMC was not plastic in response to induction. SLA and water content are indicators of nutritional quality (Díaz et al. 2001), but caterpillar growth was not affected by herbivore induction (Table 2). Hence, the induced responses observed both for trichome density and SLA have not led to increased induced resistance against Mamestra cater pillars. This may be because our populations had a high overall constitutive resistance and plants with a high constitutive resistance also tend to have less inducible resistance (Kempel et al. 2011; Campbell and Kessler 2013). Hence, we conclude that our experiment provided no evidence that selfing and outcrossing populations differ in their ability to respond to herbivory through induced resistance. 


\section{Conclusion}

Costs of selfing are pivotal in determining whether or not selfing can evolve from outcrossing ancestors (Charlesworth and Charlesworth 1987). Selfed progeny from nor mally outcrossing plant species frequently have a reduced fitness due to inbreeding depression, forming a barrier to the evolution of selfing (Husband and Schemske 1996). However, inbreeding depression is expected to disappear as selection purges the delete rious alleles that cause inbreeding depression (Lande et al. 1994; Husband and Schemske 1996; Byers and Waller 1999). By comparing performance of outcrossing and selfing populations of $A$. lyrata, we addressed whether costs of selfing beyond inbreeding depression existed. Our comparison of defence related traits and palatability to generalist herbivore caterpillars of $M$. brassicae did not reveal any differences between selfing and outcrossing populations, and thus provides no support for the hypothesis that selfing populations should be more susceptible to generalist herbivores (Johnson et al. 2009). Although herbivore damage induced changes in trichome density and SLA, our data do not support the prediction that selfing populations should have a higher inducible resistance (Campbell and Kessler 2013).

In line with earlier findings (Willi 2013), plants from selfing populations of North American A. lyrata had reduced germination rates compared to conspecific outcrossing populations, but comparable growth. However, to ultimately test the hypothesis that selfers are evolutionary dead ends (Stebbins 1957), more comprehensive assessments of the costs of selfing and the respective roles of drift load and accumulation of deleterious mutations are needed. To achieve this, future studies face the challenge of incorporating measures of seed set and seed quality over multiple generations for comparisons among outcrossing and selfing populations.

Acknowledgments We thank Barbara Mable for kindly providing the seeds that formed the basis of this experiment, Wayne Dawson for statistical advice, Christine Giele, Katya Mamonova and Carolin Bogs for practical assistance, the gardeners for their help with plant maintenance, Anne Kempel for discussion, Leon Westerd for providing caterpillar eggs and Gerald Mende and Dieter Schopper for use of the animal rearing facilities and practical advice; four anonymous reviewers and the editor for their constructive comments on the manuscript.

Compliance with ethical standards

Conflict of interest The authors declare no conflicts of interest.

\section{References}

Agrawal AA (2000) Benefits and costs of induced plant defense for Lepidium virginicum (Brassicaceae). Ecology 81:1804 1813

Baker HG (1955) Self compatibility and establishment after long distance dispersal. Evolution 9:347 349 Barton NH, Charlesworth B (1998) Why sex and recombination? Science 281:1986 1990

Bates D, Maechler M, Bolker B, Walker S (2014) lme4: linear mixed effects models using Eigen and S4. R package version 1.16 . arXiv:1406.5823v1

Burd M (1994) Bateman principle and plant reproduction the role of pollen limitation in fruit and seed set. Bot Rev 60:83 139

Busch JW (2004) Inbreeding depression in self incompatible and self compatible populations of Leaven worthia alabamica. Heredity 94:159 165

Byers DL, Waller DM (1999) Do plant populations purge their genetic load? Effects of population size and mating history on inbreeding depression. Annu Rev Ecol Syst 30:479 513 
Campbell SA, Kessler A (2013) Plant mating system transitions drive the macroevolution of defense strategies. Proc Natl Acad Sci USA 110:3973 3978

Charlesworth D, Charlesworth B (1987) Inbreeding depression and its evolutionary consequences. Annu Rev Ecol Syst 18:237 268

Charlesworth D, Morgan MT, Charlesworth B (1990) Inbreeding depression, genetic load, and the evolution of outcrossing rates in a multilocus system with no linkage. Evolution 44:1469 1489

Clauss MJ, Dietel S, Schubert G, Mitchell Olds T (2006) Glucosinolate and trichome defenses in a natural Arabidopsis lyrata population. J Chem Ecol 32:2351 2373

Darwin C (1876) The effects of cross and self fertilisation in the vegetable kingdom. John Murray, London

Díaz S, Noy Meir I, Cabido M (2001) Can grazing response of herbaceous plants be predicted from simple vegetative traits? J Appl Ecol 38:497 508

Falahati Anbaran M, Lundemo S, Agren J, Stenoien HK (2011) Genetic consequences of seed banks in the perennial herb Arabidopsis lyrata subsp petraea (Brassicaceae). Am J Bot 98:1475 1485

Fisher RA (1941) Average excess and average effect of a gene substitution. Ann Eugen 11:53 63

Foxe JP, Stift M, Tedder A, Haudry A, Wright SI, Mable BK (2010) Reconstructing origins of loss of self incompatibility and selfing in North American Arabidopsis lyrata: a population genetic context. Evolution 64:3495 3510

Gols R, Wagenaar R, Bukovinszky T, van Dam NM, Dicke M, Bullock JM, Harvey JA (2008) Genetic variation in defense chemistry in wild cabbages affects herbivores and their endoparasitoids. Ecology 89:1616 1626

Hayes CN, Winsor JA, Stephenson AG (2004) Inbreeding influences herbivory in Cucurbita pepo ssp. texana (Cucurbitaceae). Oecologia 140:601 608

Heller R, Maynard Smith J (1978) Does Muller's ratchet work with selfing? Genet Res 32:289 293

Hoebe PN, Stift M, Tedder A, Mable BK (2009) Multiple losses of self incompatibility in North American Arabidopsis lyrata? phylogeographic context and population genetic consequences. Mol Ecol 18:4924 4939

Hoebe PN, Stift M, Holub EB, Mable BK (2011) The effect of mating system on growth of Arabidopsis lyrata in response to inoculation with the biotrophic parasite Albugo candida. J Evol Biol 24:391 401

Husband BC, Schemske DW (1996) Evolution of the magnitude and timing of inbreeding depression in plants. Evolution 50:54 70

Igic B, Bohs L, Kohn JR (2006) Ancient polymorphism reveals unidirectional breeding system shifts. Proc Natl Acad Sci USA 103:1359 1363

Igic B, Lande R, Kohn JR (2008) Loss of self incompatibility and its evolutionary consequences. Int J Plant Sci 169:93 104

Ioerger TR, Clark AG, Kao TH (1990) Polymorphism at the self incompatibility locus in Solanaceae predates speciation. Proc Natl Acad Sci USA 87:9732 9735

Johnson MTJ, Smith SD, Rausher MD (2009) Plant sex and the evolution of plant defenses against her bivores. Proc Natl Acad Sci USA 106:18079 18084

Karkkainen K, Agren J (2002) Genetic basis of trichome production in Arabidopsis lyrata. Hereditas $136: 219226$

Kempel A, Schadler M, Chrobock T, Fischer M, van Kleunen M (2011) Tradeoffs associated with con stitutive and induced plant resistance against herbivory. Proc Natl Acad Sci USA 108:5685 5689

Kivimaki M, Karkkainen K, Gaudeul M, Loe G, Agren J (2007) Gene, phenotype and function: GLAB ROUS1 and resistance to herbivory in natural populations of Arabidopsis lyrata. Mol Ecol 16:453 462

Lande R, Schemske DW, Schultz ST (1994) High inbreeding depression, selective interference among loci, and the threshold selfing rate for purging recessive lethal mutations. Evolution 48:965 978

Leimu R, Fischer M (2010) Between population outbreeding affects plant defence. PLoS One 5:e12614

Leimu R, Kloss L, Fischer M (2008) Effects of experimental inbreeding on herbivore resistance and plant fitness: the role of history of inbreeding, herbivory and abiotic factors. Ecol Lett 11:1101 1110

Levin DA (1975) Pest pressure and recombination systems in plants. Am Nat 109:437 457

Lewis MCF, Karrow PF, Blasco SM, McCarthy FMG, King JW, Moore TC, Rea DK (2008) Evolution of lakes in the Huron basin: deglaciation to present. Aquat Ecosyst Health 11:127 136

Loe G, Torang P, Gaudeul M, Agren J (2007) Trichome production and spatiotemporal variation in her bivory in the perennial herb Arabidopsis lyrata. Oikos 116:134 142

Mable BK, Adam A (2007) Patterns of genetic diversity in outcrossing and selfing populations of Ara bidopsis lyrata. Mol Ecol 16:3565 3580

Mable BK, Robertson AV, Dart S, Di Berardo C, Witham L (2005) Breakdown of self incompatibility in the perennial Arabidopsis lyrata (Brassicaceae) and its genetic consequences. Evolution 59:1437 1448

Muller HJ (1964) The relation of recombination to mutational advance. Mutat Res Fundam Mol Mech Mutagen 1:2 9 
Puentes A, Agren J (2013) Trichome production and variation in young plant resistance to the specialist insect herbivore Plutella xylostella among natural populations of Arabidopsis lyrata. Entomol Exp Appl 149:166 176

R Core Team (2014) R: a language and environment for statistical computing. R Foundation for Statistical Computing, Vienna

Ross Ibarra J, Wright SI, Foxe JP, Kawabe A, DeRose Wilson L, Gos G, Charlesworth D, Gaut BS (2008) Patterns of polymorphism and demographic history in natural populations of Arabidopsis lyrata. PLoS One 3:e2411

Rutter MT, Shaw FH, Fenster CB (2010) Spontaneous mutation parameters for Arabidopsis thaliana measured in the wild. Evolution 64:1825 1835

Shaw RG, Byers DL, Darmo E (2000) Spontaneous mutational effects on reproductive traits of Arabidopsis thaliana. Genetics 155:369 378

Sicard A, Lenhard M (2011) The selfing syndrome: a model for studying the genetic and evolutionary basis of morphological adaptation in plants. Ann Bot 107:1433 1443

Sletvold N, Huttunen P, Handley R, Karkkainen K, Agren J (2010) Cost of trichome production and resistance to a specialist insect herbivore in Arabidopsis lyrata. Evol Ecol 24:1307 1319

Sletvold N, Mousset M, Hagenblad J, Hansson B, Agren J (2013) Strong inbreeding depression in two Scandinavian populations of the self incompatible perennial herb Arabidopsis lyrata. Evolution 67:2876 2888

Stebbins GL (1957) Self fertilization and population variability in the higher plants. Am Nat 91:337 354

Stephenson AG, Leyshon B, Travers SE, Hayes CN, Winsor JA (2004) Interrelationships among inbreeding, herbivory, and disease on reproduction in a wild gourd. Ecology 85:3023 3034

Stift M, Hunter BD, Shaw B, Adam A, Hoebe PN, Mable BK (2013) Inbreeding depression in self incompatible North American Arabidopsis lyrata: disentangling genomic and $\mathrm{S}$ locus specific genetic load. Heredity 110:19 28

Takebayashi N, Morrell PL (2001) Is self fertilization an evolutionary dead end? Revisiting an old hypothesis with genetic theories and a macroevolutionary approach. Am J Bot 88:1143 1150

van Leur H, Vet LE, van der Putten WH, van Dam NM (2008) Barbarea vulgaris glucosinolate phenotypes differentially affect performance and preference of two different species of lepidopteran herbivores. J Chem Ecol 34:121 131

Vergeer P, Kunin WE (2011) Life history variation in Arabidopsis lyrata across its range: effects of climate, population size and herbivory. Oikos 120:979 990

Willi Y (2013) Mutational meltdown in selfing Arabidopsis lyrata. Evolution 67:806 815

Wright SI, Nano N, Foxe JP, Dar V U (2008) Effective population size and tests of neutrality at cytoplasmic genes in Arabidopsis. Genet Res 90:119 128

Wright SI, Kalisz S, Slotte T (2013) Evolutionary consequences of self fertilization in plants. Proc R Soc B 280:20130133

Zuur A, Ieno EN, Walker N, Saveliev AA, Smith GM (2009) Mixed effects models and extensions in ecology with R. Springer, New York 